\title{
Making sense of an innovation in a safety-critical megaproject
}

\begin{abstract}
Purpose: In megaprojects, changes in scope and organization may occur continuously. This article investigates how actors in a project network make sense of a safety-related process innovation introduced during the design phase.

Design/methodology/approach: An inductive single case study of an ongoing nuclear power plant project in Europe was employed to elucidate sensemaking processes using a narrative approach.

Findings: The empirical analysis yielded nine distinct narratives regarding the innovation each advancing a different account of the rationale for implementing the new method, and the subjects, objects and implications of the change. The findings suggest that actors' differing framings of innovation may increase ambiguity and equivocality.

Originality/value: These insights augment existing knowledge of innovation management and system safety in safety-critical megaprojects by revealing project actors' discrepant sensemaking processes with regard to innovations. To successfully manage sensemaking and its consequences for innovation adoption, managers need to take account of any such discrepancies in sensemaking processes.
\end{abstract}

Paper type: Research paper

\section{Introduction}

Ongoing changes of scope and organizational set-up are an inherent element of high-technology megaprojects, which are typically characterized by organizational and institutional uncertainty (Flyvbjerg et al., 2003; Gil and Tether, 2011). Management of uncertainty and innovation in these multi-organizational networks has attracted increasing research interest (Floricel and Miller, 2001; Bechky and Okhuysen, 2011; Davies et al., 2014), including how actors pursue and engage with the development, implementation and exploitation of novel ideas, schemes or formulae (Van de Ven, 1986) during the project lifecycle. Previous studies have explored the activities of project managers in managing innovations (Davies et al., 2014), as well as organizational capabilities (Dodgson et al., 2015) and arrangements that support innovation in megaproject contexts (DeBarro et al., 2015).

To date, most of this research has focused on the challenges, enablers and organizational arrangements that facilitate innovation and the development of new ideas (DeBarro et al., 2015). Much less attention has been devoted to analyzing how megaproject participants interpret new ways of doing things - that is, the sensemaking processes through which actors interpret and frame those innovations - amid everyday complexity and uncertainty. Understanding how practitioners make sense of innovations is a crucial concern, as this ultimately determines whether and how innovations are understood, accepted and applied within the project network. This is especially important in safety-critical megaprojects such as nuclear power plant projects, where sensemaking processes are triggered by unexpected events, ambiguity and change. 
The present study conceives of the project organization as a project network (DeFillippi and Sydow, 2016), in which multiple firms jointly design and implement the desired end product—in this case, a nuclear power plant, where safety is always the first priority. The study explores how members of the project network made sense of a process innovation that introduced new safety requirements during the design stage of an ongoing nuclear power plant megaproject in Europe. The research question was formulated as follows: How do the actors make sense of an innovation introduced in a safetycritical megaproject? To address this question, actors' sensemaking was explicated through narratives that emerged from inductive analysis of the data, focusing in particular on the implications of the safety-critical context. Narratological approaches to sensemaking emphasize the role of narratives and stories in actors' efforts to construct and frame their changing reality. Although such studies are increasingly common, existing innovation and megaproject research has largely neglected both sensemaking and narrative approaches, with few exceptions (Sergeeva, 2014).

The study makes three distinct contributions to the literatures on innovation in megaprojects and safety-critical projects. First, by capturing project network actors' multi-faceted sensemaking processes, it challenges the prescriptive view that still dominates the discourse around project innovation management. Second, as most prior research related to single-organization settings, the study provides new insights into innovation adoption in project network contexts. Finally, the findings illuminate how the safety-critical context affects actors' sensemaking processes.

\section{Theoretical background and research context}

\subsection{Megaprojects as a complex network of organizations}

In the existing research, megaprojects are viewed as complex systems that entail significant uncertainty (Floricel and Miller, 2001; Miller and Lessard, 2001) over a long lifecycle (Artto et al., 2016). Megaprojects are established to design and implement end products involving core technologies in multiple sectors, including rail and road transportation (Flyvbjerg et al., 2003); airports (Brady et al., 2007; Gil and Tether, 2011); oil refineries (Turkulainen et al., 2015); nuclear power plants (Ruuska et al., 2011); and nuclear decommissioning (Invernizzi et al., 2016). In designing and implementing a megaproject, the global context contributes to the complexity of the project (Orr and Scott, 2008; Scott et al., 2011).

Megaprojects are commonly characterized as hierarchical contract organizations (Morris and Hough, 1987). According to Levitt and March (1995), the purpose of this contract organization is to create a cooperative system based on common objectives, incentivizing contractors through appropriate contracts and pricing. Miller and Lessard (2008) argued that large projects should be governed and managed as flexible systems, looking beyond contractual issues. In an analysis of supply networks for the Olkiluoto 3 and Flamanville 3 nuclear power plant projects, Ruuska et al. (2011) supported Miller and Lessard's view that multi-firm projects should be viewed as supply networks characterized by a complex and networked organizational structure and proposed a shift in governance from an emphasis on market and hierarchy toward novel network-level mechanisms such as self-regulation.

Megaprojects are intentionally created strategic networks (Järvensivu and Möller, 2009; Raab and Kenis, 2009), in which the project network serves as a temporary organization that develops the desired end product. For project implementation, and to fulfill inherent requirements such as safety, 
actions, actors, rules, procedures and resources must be defined and then coordinated and controlled by managing (Järvensivu and Möller, 2009), governing (Jones et al. 1997; Provan and Kenis, 2008) or orchestrating (Dhanaraj and Parkhe, 2006; Hinterhuber, 2002) the network. Existing research tends to view the management of purpose-focused networks as a centralized activity, in which a few dominant organizations form and orchestrate transactional business relationships with other organizations (Dhanaraj and Parkhe, 2006; Choi et al., 2001). In such networks, these hub firms hold the bargaining power and control or orchestrate (Hinterhuber, 2002) business transactions across the entire network (Henneberg et al., 2010). Consequently, the network's goals and joint actions reflect the goals of the hub firm (Möller et al., 2005), which may not necessarily serve the intentions and goals of all participating organizations.

While networks can be intentionally configured and managed by a central firm (Jarillo, 1988; Hinterhuber, 2002; Dhanaraj and Parkhe, 2006; Müller-Seitz, 2012), the differing business interests of member organizations limit the hub firm's influence on other member organizations in the network. In previous research on megaprojects (Lundrigan et al., 2014), theories of collective action (Ostrom, 1990; Olson, 1965) and a commons approach (Ostrom, 1990) have been applied to explain how management depends on the joint efforts of all project network members rather than on the hub firm alone. Other research has explored joint routines (Matinheikki et al., 2016) and collective development of system-level goals (Järvensivu and Möller, 2009; Möller and Rajala, 2007), but little is known about how interim changes in collective actions and joint routines may affect the network and its performance.

\subsection{Megaprojects in the nuclear power industry}

Nuclear new builds are organized and implemented through multi-party, multi-national project networks. Although these megaprojects are global in nature, they are often characterized as significant national "landmarks" in terms of investment, political commitment, labor force effort and competence base, with long-term economic, environmental and societal impacts (Brookes and Locatelli, 2015; Zidane et al., 2013). In their recent review of the megaprojects literature, Saunders and Townsend (2018) focused in particular on new nuclear builds and identified a number of characteristic features that included trait-making, excessive timescale and cost, high levels of uncertainty and ambiguity and exceptional organizational complexity. In their view, the challenges posed by new nuclear build projects increasingly extend beyond technological concerns to institutional, political and societal issues.

In these complex nuclear projects, safety cannot be ensured by technical means alone, as human and organizational factors play a key role in shaping the changing vulnerabilities and hazards during the project lifecycle. From a systemic perspective, safety emerges from the dynamic interactions between individuals, organizations and technology (Woods and Hollnagel, 2006; Reiman and Oedewald, 2007; Oedewald et al., 2011). The essence of safety culture is the ability and willingness of all participating organizations to understand safety, hazards and means of prevention, aswell as the ability and willingness to act on these in practice (Reiman et al., 2010, 2012; Oedewald et al., 2011).

In the pre-operational phases of nuclear projects, including design, construction, installation and commissioning, developing a safety culture may sometimes be perceived as separate from other core issues. One reason for this is that nuclear safety risks are less tangible, obvious or pressing than 
concerns about costs and scheduling (IAEA, 2012). Nevertheless, safety culture remains an important aspect of organizational culture, contributing to plant efficiency and long-term safety. In large and complex projects, safety management is highly dependent on management beliefs, assumptions and understandings regarding organizational behavior and safety (Reiman and Rollenhagen, 2011). Moreover, in a project network, characterized by everyday and strategic decision-making, safety depends on commitment and continuous improvement at all levels and among all actors. While safety has traditionally been understood as a lack of accidents or incidents, there is increasing emphasis on a proactive approach to safety as a positive presence that enhances actors' capacity to cope with the demands and variability of daily work (Hollnagel, 2014; Reiman and Rollenhagen, 2011, 2014).

In large complex projects, actors will inevitably perceive and interpret the project in their own ways, making it challenging to gain an accurate "big-picture" view of system dynamics. In a nuclear power plant project, it is essential from the outset to take a long-term view of the functionality and safety of the end product, and to balance this against short-term goals. In the nuclear industry, design is highly regulated, both nationally and by international standards and guidelines such as those of the International Atomic Energy Agency (IAEA). The companies involved in the different phases of a nuclear project may come from different industrial domains and are not necessarily familiar with the context and its specific requirements. The same is true of engineering companies that move beyond their domestic market and must adapt to different regulatory requirements and practices. In a nuclear new build, the "design basis" of systems, structures and components - that is, their ability to withstand a certain range of conditions and events - must be proved and thoroughly documented (IAEA, 2007), and making sense of these requirements and adapting to new working practices (e.g., documentation of work processes) may prove challenging and time-consuming.

\subsection{Sensemaking as a methodological perspective}

The present study explores the processes of interpretation, reflection and meaning production associated with the introduction of a new requirements management tool in a nuclear megaproject organization through the theoretical lens of sensemaking (Weick, 1995; Weick et al., 2005). This theoretical perspective is appropriate for present purposes because it facilitates exploration of the context-specific processes used by individuals to make sense of phenomena they encounter (Dutton and Dukerich, 1991) and how they relate and react to those phenomena (Weick, 1999). As sensemaking involves interpreting, reflecting on and assigning meaning to what one encounters its role is especially significant when organizations undergo changes. It is through the process of sensemaking that people enact and socially construct their realities that is then interpreted and assigned a meaning. To that extent, sensemaking is much more wide-ranging than mere interpretation, as it takes account of people's innovativeness and latitude in constructing the social and physical worlds (Weick, 1995).

Additionally, sensemaking is always both retrospective (Weick, 1995; Weick et al., 2005) and futureoriented or prospective (Weick et al., 2010) — that is, sensemaking occurs after something has happened, but new representations of the present and future paths are also constructed. Sensemaking must have an object-otherwise, there is nothing to make sense of-but this may be a social construction as much as a "real" occurrence (Vaara, 2002). Situations of crisis or change that involve puzzling or troubling data provide a meaningful context for exploring individual and group sensemaking (Weick, 1995). Importantly, while sensemaking may generate shared frameworks, 
consensus and understandings that facilitate collective behavior, it may equally lead to differences and discrepancies in shared meanings (Brown et al., 2008; Weick, 1995). These discrepancies and the rationales that underpin them remain largely unexplored (Brown et al., 2008).

Stories, verbal descriptions and other communications shared and negotiated with other organizational actors play a crucial role in sensemaking processes (Brown et al., 2008; Brown, 2006; Weick et al., 2010). As these processes inherently involve narrativization, a narratological approach can reveal how individuals use narratives to construct their reality in the face of change by agreeing, negotiating or contesting shared meanings (Brown et al., 2008). On this view, narrative is the "primary cognitive instrument (Mink, 1978: 131) and is commonly linked to sensemaking as an overall theoretical frame (Vaara et al., 2017). According to Vaara et al. (2017), organizational narratives are "temporal, discursive constructions that provide a means for individual, social and organizational sensemaking and sensegiving". While the terms narrative, account and story are often used interchangeably (Brown and Jones, 1998; Humphreys and Brown, 2002; Maclean et al., 2012), there is a view that, unlike stories, narratives do need not be fully-fledged descriptions or plots with a beginning, middle and end but may instead be fragmented and incomplete (Vaara et al., 2017).

Crucially, however, narratives are always temporal and context-dependent, embedded in a multilayered structure that extends from the broader society to the micro-level use of discursive strategies (Sergeeva, 2014). By capturing the composite narratives of organizational groups, representing their interpretative patterns and collective meanings (Balogun and Johnson, 2004), it is possible to compare these groups and their sensemaking processes. In situations involving change, competing narratives reveal how that change is interpreted and framed. Identifying these narratives may be considered as the first step toward understanding how the interpretations, schemes and sense people make translate into the actual behaviors, action and practice of organizing.

Project management scholars have utilized this sensemaking perspective in various contexts. In particular, cross-cultural projects involving a diverse set of stakeholders from different backgrounds offer an ideal setting in which to explore sensemaking processes and their implications for project performance (Fellows and Liu, 2016; Tukiainen et al., 2010; Dyer, 2016). In relation to cultural sensemaking, Fellows and Liu's (2016) review of the sensemaking literature included recommendations for sensemaking to enhance project relationships. In a study that focused on sensemaking processes associated with unexpected stakeholder conflicts in a cross-cultural global project, Tukiainen et al (2010) showed that although these processes may differ radically across project participants, decoupling strategies can help actors to cope with divergent interpretations. Dyer (2016) noted the crucial role of managers in making sense of the differing worldviews of megaproject stakeholders in ways that are culturally sensitive. In their study of intermediary objects of design, Papadimitriou and Pellegrin (2007) identified the role of boundary objects of various kinds for sensemaking within projects. Sensemaking processes have also been explored in the context of service-led projects (Alderman et al., 2005), change programs (Pollack et al., 2013) and value management practices (Thiry, 2001). Interpretative approaches conceptualize narratives as individual constructions of project-related phenomena, but relatively few empirical project studies to date have linked sensemaking and narrative approaches (Sergeeva, 2014).

\section{Methodology}


The general aim of the present study was to understand how network actors made sense of the adoption of innovation during a safety-critical megaproject. An in-depth inductive single case study (Yin, 2009) was employed to elucidate sensemaking processes using a narrative approach. Although single cases have certain limitations, small sample size was not an issue, as inductive case studies are not concerned with generalizability. The case study approach was considered appropriate as it supports rich analysis and in-depth understanding of narrative sensemaking constructions in a changing real-life context (Yin, 2009).

\subsection{Case description}

The research setting was the design stage of a European nuclear power plant project. Organizations in the project network included the project owner, the plant supplier, the plant supplier's main contractor and other subsuppliers and subcontractors, including the main equipment supplier, the general designer of the power plant and the chief process designer. The project owner was also responsible for licensing and had entered a turnkey contract with the plant supplier. The main contractors had substantial previous experience of building similar nuclear plants, which was exploited in creating the conceptual and plant-level documentation. However, it became evident that the proposed structure and content of the documentation would make it challenging to secure a construction license. To address this challenge, a new licensing and safety design method and tool for nuclear facilities was introduced in the project during its design phase. The present analysis explores this innovation and its adoption within the project network. The selected phenomenon was considered suitable for the purposes of our analysis on sensemaking because of the dynamic and evolving nature of the change and the ambiguity it entailed. The innovative methodology and a tool supporting new licensing and safety design method were developed by another power company, which had utilized it successfully for configuration management and licensing of a nuclear facility that met regulatory requirements for nuclear safety. As implementation of this new methodology was ongoing at the time of data collection, it was possible to capture sensemaking processes in real time.

\subsection{Data collection and analysis}

Eleven semi-structured interviews were conducted in October-November 2016 with informants selected by the owner company. Semi-structured interviews continue to be among the most common sources in narrative research (Brown et al., 2008; Denzin and Lincoln, 2013). Rather than the completely open form of interviews typical of narrative interviewing (Vaara, 2002), the widely used semi-structured approach allowed the interviewees to address certain pre-designed themes related to the introduction of the new tool, as well as facilitating follow-up questions about the stories that emerged.

The interviewees were drawn from different organizational units and hierarchical levels, but most were managers and directors with extensive experience in the nuclear field. Each interview lasted about ninety minutes, with at least two researchers present in most cases. The interview themes related to the overall organizing and coordination of the project network, the introduction of the new licensing and safety design method and the interviewees' ensuing experiences. All but one of the interviews were recorded (with the informant's consent) and were then summarized and analyzed by the researchers - first individually and then in workshops. All data were content analyzed. The first step was to identify emerging themes and indicators that related to the introduction of the new method. 
In the second formal coding round, various narratives and interpretations began to emerge, and the researchers shared and discussed their thoughts, combining similar themes to elucidate the meanings that the interviewees assigned to the innovation and the interpretative frameworks they used. Nine different narratives emerged, each advancing a different account of the rationale for implementing the new method, and the subjects, objects and implications of the change. These narratives served to clarify how such innovations are introduced and adopted and what kinds of implications they may have for the actions, decision-making and behaviors of actors in the project network.

\section{Results: Sensemaking narratives of innovation in a nuclear power plant project}

The different narratives revealed the participants' assumptions and interpretations regarding the innovation's antecedents, rationale and purpose, as well as the perceived implications of its implementation.

\section{Engineering tool narrative}

The sensemaking processes that informed the engineering tool narrative offered a rational explanation of the new approach, which was interpreted as a necessary technical tool for managing safety requirements. The underlying tone of the narrative was that the design of nuclear installations is complex and must adhere to strict safety requirements. Managing the design process depends on a tool that elaborates requirements in a structured way, providing transparency and traceability and supporting a top-down system engineering approach, in which design flows from plant level down to system and component levels: "The method takes into account the nuclear laws' requirements; the design process proceeds from a plant-level understanding to the architecture and system levels and ends with the component level." Here, the dominant discourse indicates that the new tool is well aligned with accepted methods for requirements management when designing complex systems. The main benefit of this particular tool was perceived to be its applicability to industry and country contexts: "It provides a clear picture of how the regulatory and safety-related requirements affect design."

This narrative emphasizes that the tool is based on "simple requirements-based engineering." The object is the management that introduced it, and implementation of the tool was seen to be supported by adequate training. In this regard, the narrative highlights the consulting services provided by the supplier. The rationality of work coordination, systematic and rapid review and approval processes are also highlighted on the grounds that "at any given point, you need to have a limited amount of documents in your mind when you review the documents." The innovation was seen to prove the correctness of the design process and to improve safety: "By utilizing the tool, we have found (and corrected) some weaknesses in our design because this is a very systematic approach." From an engineering tool perspective, the extent to which the tool should be used beyond plant-level management and safety-related design documentation had yet to be decided. In summary, adoption of this tool was seen to ground the design in system engineering principles, facilitating the creation of systematic, transparent documentation that could be used throughout the lifecycle of the plant.

\section{Efficiency and effectiveness narrative}

The efficiency and effectiveness narrative highlighted the rationalized technical benefits of adopting the tool, which is perceived to improve both the efficiency of design processes and the quality and 
safety of the end product. The innovation was seen to provide a means of coordinating the activities of the different parties involved in the design and approval processes, which are the object of change: "the message is that we can succeed together." The improvement in coordination and efficiency is seen to relate especially to design document review and approval processes, where all main actors must collaborate and coordinate their work. Having a shared method for requirement management is especially important in this context, where actors originally differed in their understandings of the process and the documentation required to validate and certify the design.

In this narrative, the implementation of the tool was also seen to have created some additional work and documentation, impacting in the short term on scheduling and efficiency. However, the perceived benefits included resource savings, positive effects on the schedule and a more transparent and predictable process that is easier to control: "It is beneficial to use and will benefit the project, although it means additional burden, resources, and time delays." The perceived effectiveness of the design also related to the long-term success of the project over the next 60 years. This narrative suggests that the systematic design is also easier to maintain over the lifecycle of the project: "We are building a solid foundation, and there will be benefits in the future. You cannot argue with this-it provides structure and safety logic."

\section{Relational narrative}

The relational narrative centered on how the introduction of the tool changed inter-organizational relationships. The interviewees reflected on how the associated training sessions and meetings helped to build more embedded relationships, supporting the development of trust and personal relationships and facilitating collective learning. It was notable that these events afforded an opportunity for actors to demonstrate their technical knowledge when discussing details of the technical design, contributing to the personal and impersonal trust that depends on confidence in other actors' technical capabilities and competences: "The workshops raised many questions, some very detailed, which were addressed and answered. This is a time for really personal discussions too, which is not natural for all managers, but here we had a place for it."

The interviewees also acknowledged that the initial resistance to change ultimately proved very helpful in promoting a relational orientation: "There were quite intensive discussions, and there were differing opinions, but in the end, they supported the collaboration." According to this narrative, a key rationale for introducing the tool was to facilitate relationship building, and the innovation was seen as a catalyst for boundary-spanning activities between organizations that were previously seen to be working well on their own design tasks but without routinized processes for wider interaction.

In this narrative, the object of change was the network of key project actors and their relationships, and sensemaking focused on the tool's role as a mechanism for developing those relationships. The analysis reveals that the tool and associated interactions served as boundary objects that facilitated interaction between actors and more embedded relationships based on trust and commitment. In particular, the transparency of the design documentation was considered central to establishing and maintaining trust.

It is also clear from the data that the tool created a shared and structured terminology that supported communication and a collective understanding of other issues related to the design process: "There is now a new terminology for communication that highlights the need for reviews, and now we are 
beginning to get invitations to designers' internal review meetings." In short, this narrative emphasized the tool's relational effects, including the establishment of a joint language and improved information sharing, communication and trust.

\section{Cross-cultural narrative}

The cross-cultural narrative highlighted how the introduction of the new tool encouraged crosscultural interaction between network members. On this view, a key rationale for introducing the tool was the need to bridge the cultural distance between the different nationalities in the project network, especially in terms of localized knowledge of operating and licensing requirements in the country in question.

Interestingly, the dominant narrative associated nationality with different ways of thinking about design: "The introduction of the tool requires a culture change, maybe a mindset change, and the [foreigners] need to understand that this design process should start from the top and continue downward." The objects of change in the cross-cultural narrative were foreign actors in the network; active agency was associated with domestic actors, including the project owner and the regulatory body.

The use of a concrete tool to align design activities with the local context was also seen as a positive and systematic way of bridging the cross-cultural divide, which is always a source of ambiguity. Rather than general discussion of cross-cultural co-operation, the introduction of a concrete tool created a technical space in which other issues related to cross-cultural tensions could be addressed. In this regard, the joint boundary language of the tool was a key building block, helping to standardize and harmonize communication between different nationalities.

According to this narrative, introducing the new tool was also seen to have positive implications for the foreign actors: "Our country's nuclear regulatory body is one of the strictest, so this is a learning opportunity for them too from their cultural perspective." Introducing the tool also made different ways of thinking more visible and concrete, helping to build collective understanding and capabilities in the network: "You always have these difficulties in understanding how people think-how a foreign origin expert might think, how he is thinking when he says something. The introduction of this new tool makes these things visible, and then it's easier to build on that." The cross-cultural narrative interprets the tool as a driver for explicating less visible underlying cross-cultural differences and values that are taken for granted, so providing a platform for reducing that distance.

\section{Control narrative}

In the control narrative, the rationale for the innovation was seen primarily in terms of visible and traceable processes, offering better transparency regarding safety requirements and control of the design process. Here, the dominant discourse relates to reducing the uncertainty inherent in the management of complex projects: "There was a lot of uncertainty before, and now that we know what the processes are, we can control the suppliers better. We think their design is very good, but the processes need to be under control too."

The key objects of change here are the design contractors while the subject is the project owner's operational management. The narrative focuses on the ability to control things better-especially the schedule - making it possible to trust that schedule: "At the end of the day, I would like to have a 
good schedule that I can trust and follow-then it is much easier to schedule your tasks. Now, we have tasks and deadlines, and it is much easier to plan and control what you will do every day." The control narrative clearly reflects the actors' added confidence in monitoring of the project network and indicators facilitating early detection of schedule delays or coordination problems.

\section{Hope narrative}

In the hope narrative, the perceived rationale for implementation of the new tool was that the supplier's traditional design process did not ensure successful licensing process: "During the first year, we understood that we would have difficulties if we continued with the [supplier's] normal practice." Given this uncertainty about the project's course at this critical point, the tool was seen as a means of saving the project, as looking inward at the technical efficiency of "our project" identified a need for a new approach to the design process and related documentation: "Something like this methodology was really needed. If you don't understand the requirements, the business and the local regulatory body's approach, you will be constantly surprised."

These interviewees perceived the tool as "conditionally proven." On the one hand, it was accepted by the regulatory body and had proved capable of ensuring approval, but it was still under development and remained as yet unproven in any broader context (e.g., the plant as a whole): "[this is] a new context for applying the methodology [to a whole new build] but also for its developers: I have a feeling that [the tool's] development is just one step ahead or sometimes just keeping up with the project."

In the hope narrative, the supplier and major actors in the supply chain are seen as the object of change. The analysis revealed that implementation of the tool was also a way of bringing additional resources and expertise to the project. The focus was on achieving agreement to use the new approach, which had been created and tested by the tool's developers for another project: "What was quite convincing was the automation renewal project. They explained that after developing and using the methodology, everything ran smoothly." In essence, the hope narrative highlights how implementation of the tool brought hope for the future, and the main implication is the shared perception that the project is on the right track: "It has to be a success story." "Until now, it seems like a success story; we are still waiting to reach the goal and obtain the license, but I think we are on the right track." "To me, it brings hope to the project. I was quite convinced and I still am, that this is the only way forward ... I do not know about the others, there is skepticism when things change."

\section{Capability narrative}

In the capability narrative, one of the key rationales for introducing the tool is the need to create organizational and project network-level capabilities to manage the complex design process. According to the data analysis, this reflects a recognition that the project was too dependent on implicit knowledge and ways of doing things, which was considered problematic: "Experienced people know how to do it; they have worked on projects so many times that they have no timetableeverybody just knows what to do and when. This is something that does not suit local or national nuclear requirements. "In this narrative, implementation of the tool helps to make tacit knowledge explicit and indirectly supports the transition from person-related competences to organization-level and network-level capabilities, ensuring that knowledge remains within the organization or network 
and is not lost as a consequence of personnel turnover: "We can now take a person from the marketplace and tell them: 'These are requirements, everything is now on paper and in databases' ... we can change people."

The tool is seen here as a novel developer of competence and capability that supports proactivity. In addition, interviewees noted a unique opportunity to further develop the tool during the project, although this was seen to require high level skills and big picture thinking; as one interviewee put it, "This method requires top-level guys." According to this narrative, implementing the change involved learning new practices and new ways of thinking, which the experienced interviewees perceived as quite uncomfortable.

The key activities in implementing the change were training and the use of databases and standardized document structures to manage the wide variety and high volume of requirements. While the tool developer provided consultancy, insufficient training was identified as a concern, although it was acknowledged that not everyone needed to know the new tool in detail. The object of change here was the project network, and the subject of change was the power company that developed the tool and the regulator.

In this narrative, the introduction of the new tool is also seen to have very positive implications for supplier capability development, especially in terms of understanding local requirements and European nuclear industry practices: "[the tool] makes the review work much easier; we can be much more confident that we fulfill the nuclear safety requirements." The key implication is the move toward ensuring continuity of design knowledge and competencies, as that knowledge is no longer person-centered. In that sense, the tool was seen to promote learning practices in the project network, minimizing the risk of losing critical knowledge if individual engineers left the organization.

\section{Ambiguity narrative}

The ambiguity narrative highlights the "big and difficult" change triggered by the management decision to implement the new tool, with a lot of uncertainty and unclear targets, as the following quotes illustrate.

"It has proved too complex — much more complex that I initially thought."

"If it is difficult for me, who was involved from the beginning, it must be very difficult for other people who come to work with this system."

"It's a heavy, complicated approach-it is time- and resource-demanding ...Some individuals do not support the methodology because it means changes in their practices, and as we had no contractual tools to require this, we had to use other arguments."

"This is not easy; you need to retain all the sequences and interfaces in your head."

The key theme of this narrative is resistance to change; the tool was seen as complex, heavy, difficult to learn and demanding to put into use. To some extent, the interviewees normalized the change by acknowledging that it is natural to experience many difficulties when implementing such a largescale and challenging innovation. The objects of change here are the different parts of the owner's organization and the supplier's side. The key event is the justification of this change, which includes convincing the supplier and other key actors in the supply chain that this tool is needed, dealing with 
change resistance and the challenges associated with learning how to use the tool. Resistance to change related mainly to the difficulty of changing long-established and proven ways of working: "There is still some resistance. [Name of company] has really been against this methodology; they don't want to change their documents... They say they will not change their existing documentationthat they will explain how they fulfill these methodological requirements-so there will be some new external documentation." Implementation of the tool was also seen to increase workloads: "They are not against the methodology itself but the fact that it brings extra work, and it is not in their contract. Even people at [name of organization] now say that this work is too big-work without known purpose." "That is additional work, beyond normal documentation-this is something added on top of that."

The ambiguity narrative clearly reflects the uncertainty experienced by the interviewees: "Nobody knows what the consequences will be in the end...It's hard to understand at this scale-the whole plant. There are only a few people with this high level of knowledge."

"When you learn the method, then it's easy or...easier-I am not sure if I can call this method easy. If we had more time ... maybe more training is needed."

The ambiguity narrative also reveals some underlying tensions within the project-for example, between management and engineers:

"It is a sensitive topic to discuss. Few people understand it. A few people who are working with it are satisfied; the others are in a black box that causes only troubles - they don't see the benefits."

"In my opinion, these training issues are generally much underestimated. Management have their own view on the project ... engineers need to work with these and explain how to do it [...] they have the same aim, but engineers are more detail-focused - they will always have more questions.",

The main implication of the ambiguity narrative is that implementation of a complex tool for requirements management triggered a complex process of change in this large international project network. As with any large-scale change, this naturally surfaces different opinions, tensions and perspectives within the project network, and management needs to recognize and balance these nontechnical issues.

\section{Legitimization narrative}

In the legitimization narrative, the core reason for the change is compliance with local regulatory requirements for nuclear safety. For these interviewees, the main challenge of the design process was to create documentation that would meet regulatory requirements. This interpretation does not underestimate the importance of safety, but neither is it regarded as an important problem: "They have already designed functions; this is just to show systematically that all functions are designed and for systematic validation. They already have everything there; this is a licensing tool to demonstrate compliance." The main actors involved in the design were perceived as competent and capable to design a safe nuclear plant: "They know how to design, construct and operate nuclear. There are strict requirements in the suppliers' country too. However, the regulatory requirements in this country are different." Interviewees emphasized that the approach adopted prior to implementation of the new tool was not adequate to secure the plant construction and operating license; for example, the tool supports national requirements for transparency of the design process. 
According to national nuclear legislation, the safety authority plays an important role in verifying that the plant design meets regulatory requirements. In this narrative, the authority is considered a subject of change, although it is not seen to have directly influenced the decision to introduce the new tool. Instead, interviewees' sensemaking entailed a strong assumption that the new design documentation approach and format would be accepted by the national authority, as a similar approach was successfully used to win approval in another project. As a result, the main actors in the design process accepted the new approach for managing safety-related requirements. While some additional documentation had to be created, this was also seen to provide technical benefits by improving coordination among project actors.

\section{Summary of the empirical findings}

The study identified nine distinct but complementary narratives, highlighting the wide range of emerging perceptions and interpretations of change; these are summarized in Table 1. The findings indicate a fragmented sensemaking process, involving several different framings of the licensing methodology and its implementation. These perceptions were influenced by the nuclear context, entailing the need to understand, interpret and comply with multiple regulatory and contractual requirements, as well as with international standards. This influence is foregrounded especially in the engineering tool and legitimization narratives; the hope narrative is also influenced by the strict nuclear legislation requirements for securing a construction license, which were perceived as difficult to meet without the new methodology. Other narratives reflected challenges that related mainly to managing a complex multicultural inter-organizational project network.

From a cultural perspective (Schein, 1992), implementation of a novel method can be viewed as a technological means of managing design activities in response to external demands (e.g., regulatory requirements; see engineering and legitimization narratives) and to maintain internal integration (e.g., to build relationships in a diverse context: see relational and cross-cultural narratives). The tool's development was informed by certain beliefs and assumptions that were rooted in challenges and experiences within a particular context, in turn affecting the perceptions and conceptions of individuals and groups and the way the project's work was executed in practice. 


\section{<INSERT TABLE 1 ABOUT HERE>}

\section{Discussion and conclusions}

The objective of the present research was to clarify how actors in a safety-critical megaproject make sense of the introduction of a process innovation into the project network, based on the assumption that the actors' narratives reflected how they made sense of this change. The paper contributes to the literature on innovation in safety-critical megaprojects - especially the innovation adoption phase, which has received less attention (DeBarro et al., 2015). The paper also contributes to research on safety in complex safety-critical projects by elucidating the multiple interpretations of the rationale for innovation adoption and its perceived consequences. In complex and dynamic project networks, innovation adoption cannot be fully controlled by any single actor, and differing interpretations influence whether and how safety-related innovations are adopted. In contemporary nuclear projects, multiple international organizations are jointly involved in designing, constructing, commissioning and implementing an end product that will produce electricity safely and efficiently for many decades.

\subsection{Contributions to the literature on innovation in megaprojects}

The study findings indicate that adoption of the novel methodology initiated significant change in ways of operating within the project and triggered a wide range of perceptions and interpretations of the rationale and the ensuing changes. Project actors assigned different meanings to how innovation and change were handled, and these interpretations ultimately guide behavior and decision-making, potentially changing how actors perceive their own role in the megaproject network. According to these narratives, the rationale for the adoption of the innovation was to find a proven way of meeting the requirements, to enhance traceability and transparency and to provide clear documentation that would secure the regulator's approval. In a nuclear project, completing the licensing process for construction and operation represents a key milestone that commonly demands a significant investment of effort and resources. Much of this process reflects a concern to ensure that safety is always prioritized and guaranteed "by design," which ultimately makes it easier for the operators to understand the system's behavior in both normal and abnormal conditions.

The present analysis reveals the challenges posed by the involvement of multiple actors with different practices in the adoption of the innovation; the design phase must take account of the interfaces and interdependencies between systems, structures and components designed and later manufactured, constructed, installed, commissioned and operated by those different actors. A megaproject's end product is broadly defined as including both the physical product and its functionality (Morris and Hough, 1987), along with multiple non-material outcomes and effects. For example, the end product commonly includes both the capacity to create long-term operational value (Artto et al., 2016; Morris, 2013) and other outcomes that contribute to the owner's or user-operator's business success (Pinto and Rouhiainen, 2001; Shenhar et al., 2001). In the nuclear industry, plant safety and its maintenance over many decades is a key design objective and contributes directly to the project's long-term value for all project actors and for society at large. This long-term perspective is institutionalized within the industry as a natural temporal orientation and was reflected in most of the interviews with experienced 
professionals when they discussed the innovation and its adoption. Consequently, the perceptions and conceptions of individuals and groups within the project network affect the implementation and adoption of any new methodology and the formation of project structures that store relevant knowledge for newcomers and for future reference. Understanding this dynamic adds to our knowledge on innovation adoption in megaprojects (DeBarro et al., 2015) as it may enhance project actors' ability to cope with varying conditions and to exploit innovations.

These findings also reveal that sudden implementation of such a significant and far-reaching change prompts different interpretations and competing narratives, even within a single interviewee's storyline. The results concerning discrepant sensemaking processes with regard to innovations hence contribute to the nascent megaproject research addressing innovation narratives and sensemaking (Sergeeva, 2014). Clearly, adoption of this kind of innovation is a multi-dimensional phenomenon, with implications that extend beyond its original purpose. Ultimately, the innovation was seen to influence governance of the project network - that is, improvements in coordination, adaptation and safeguarding mechanisms were seen to enable multiple actors across the network to work toward shared goals (Kujala et al., 2016). For example, interviewees believed that the new method clarified how safety-related goals such as design transparency could be met to support the shared design and documentation practices and processes required for construction licensing and to improve control over the process. Simultaneously and paradoxically, however, discrepant understandings and sensemaking processes produced equivocality and ambiguity. Intriguingly, this suggests that the implementation of innovations to enhance coherence and alignment may not always produce shared narratives and meanings; on the contrary, equivocality and ambiguity may even increase.

To successfully manage sensemaking and subsequent innovation adoption, then, managers must remain open-minded and take the time to listen to other views. There is an understandable tendency to try to keep things under control by downplaying ambiguity and uncertainty and pushing the "right" interpretation of the innovation and change process. However, in line with Weick's (1979) notion of equivocality, managers need to allow different voices to be heard. Carroll (2015: 64) also referenced Weick's legacy in suggesting that "diversity of thought is costly and uncomfortable in the near term, but better in the long run." Diversity needs to be acknowledged and understood through mutual interest and respect for differing viewpoints and engagement and dialogue among all project actors.

Based on these findings, one interesting but relatively unexplored question is why innovations in megaprojects promote discrepant sensemaking and equivocality. Given the highly regulated nature of nuclear power plant projects, possible explanations may relate to organizational roles and positions, efforts to build identity and legitimacy and impression management processes (Brown et al., 2008). However, it seems important to understand the conditions in which such projects can progress despite the challenges of equivocality, ongoing tensions and sensemaking discrepancies. As the present findings show, different interpretations and "islands" of understanding with regard to innovations can co-exist within the project system at a certain stage and may even be necessary for the innovation's long-term survival. Future research should therefore investigate the temporal dynamics of fragmented sensemaking to understand how narratives unfold and contribute to innovation adoption.

\subsection{Contribution to the literature on safety-critical projects}


The current study has important implications for safety research, especially in relation to complex projects. Current approaches typically view safety as the capacity to handle known and unknown hazards under varying conditions, which implies a proactive orientation to making sense of changes in system conditions and assumes that hazards cannot be fully known. Project organizations increasingly face unexpected or novel events, which affect both organizational and interorganizational sensemaking. According to previous research, accidents often happen when "good people are struggling to make sense" (Snook, 2002: 206). In trying to account for "what is going on," the actors in the present case study described a rich landscape that influences both current and future attitudes and organizing practices. The discrepant sensemaking identified here is perhaps characteristic of complex and dynamic project networks. It is well known that sensemaking impacts decision-making (Gioia and Thomas, 1996; Rerup and Feldman, 2011) and organizational learning (Christianson et al., 2009). From a safety perspective, implementation of the novel method confronted actors in the project network with the ambiguity of the situation, affording an opportunity to reevaluate existing or prior beliefs and to actively engage in sensemaking on the basis of new information.

These findings align with Carroll (2015), who highlighted the importance of ambiguity in organizations that manage high-risk operations in a rapidly changing environment. The study investigated the process of making sense of ambiguity through dialogue and collaborative action. Carroll (2015) suggested that avoiding ambiguity is the most typical response in complex safetycritical domains; this was also apparent in the present case, as managers advanced rational explanations of the innovation and how it enhances safety. However, to capture the multiple perspectives that contribute to enhanced safety, it would be preferable to engage with diverse actors from both inside and outside the project. Although managers may initially feel uncomfortable about the plurality and diversity of sensemaking, this "requisite variety" ensures safety in the longer term. The ability and willingness to appreciate multiple diverse viewpoints helps to manage safety in temporary and ambiguous project environments, where no single actor has complete knowledge or understanding of the system. As Carroll (2014) noted, "assumptions must be held lightly in order to be testable and changeable."

The nuclear industry is very strictly regulated, and compliance with regulatory requirements is strongly emphasized. The need to comply with these requirements is well illustrated by the legitimization narrative. Interestingly, while some project actors with extensive experience of safety issues had created a working safety culture within their own national context, they needed to change their practices to meet local institutional requirements. In the eyes of these actors, the safety authority had a mandate to interpret the legislation, even if it did not officially require compliance with any particular method. Implementing change within such a strictly regulated institutional and regulatory environment can be seen to enhance safety, as every aspect is checked and verified by experts, and questions are continually asked to ensure understanding. This iterative process also develops collective project capabilities - the knowledge, practices and habits that gradually build an understanding of the complex and systemic nature of safety.

In nuclear industry projects, innovation capabilities are crucial, as opportunities to improve project efficiency and effectiveness emerge as the project unfolds. The diversity of personnel and industry newcomers requires continuous development and improvement of safety culture. In the present case, 
innovation adoption enhanced network actors' capability to communicate actively and to work through conflicts as they emerged and encouraging joint and positive responses to unexpected future events.

Finally, these findings also highlight the importance of stories and storytelling about change in safetycritical industries. In their ethnographic study, Hayes and Maslen (2015) noted that, in hazardous industries, operational safety largely depends on leaders' effective decision-making. In their ethnographic study, drawing on high-reliability theory and organizational learning and naturalistic decision-making research, they note the key role of stories and storytelling in sharing and making sense of experiences. Embedded in work practices, stories nurture the ability to imagine possible consequences and maintain safety awareness in high-risk domains, supporting organizational learning and newcomer mentoring. In the context of innovation and its adoption, story-based learning is a powerful mechanism for effective decision-making, in combination with more formal mechanisms for professional development.

\section{Managerial implications and practical recommendations}

The present findings have a number of practical implications for guiding the sensemaking process in dynamic and complex megaproject settings. The case study illustrates how what was initially seen as a "simple" act of implementing a new technical tool for the good of the project can trigger a diverse set of fragmented interpretations. Project actors' varying perceptions of the implementation process reflected different framings based on professional position, role, responsibilities, experience and background. Importantly, actors differ in their motives for accepting or resisting innovation, and managers need to understand what underpins these perceptions. The stories of key experts and senior managers typically reflect differing views of innovation and change; while senior managers tend to promote a homogeneous picture of the implementation process, experts' more divergent and ambiguous views highlight the associated challenges.

In the present case, there was no single dominant narrative, although most of the stories were based on rational analysis and interpretation. This was especially apparent in the senior managers' stories, perhaps reflecting a belief in traditional leadership that favors clear and simple messages to employees. In contrast, experts may be less satisfied with simple explanations when they encounter ambiguity. The dynamic interdependencies between human, technical and organizational factors in complex nuclear projects require a systemic approach to safety that takes account of the multiple interactions within and between individuals, teams and organizations. This may also require senior managers to adopt a more multi-dimensional and collaborative approach to communication rather than relying on oversimplified messages about why change or innovation is needed, which may fail to acknowledge the complexity of the situation.

The innovation described here was generally seen as just a tool for safety-related design documentation, based on well-known principles of system engineering and requirements management. However, implementing that tool had many implications that in themselves constituted organizational change. The project's upper management may believe it has a good overall grasp of how diverse information sources and ongoing communication contribute to implementing change, but an awareness of the spectrum of perceptions and interpretations across different key groups enriches understanding of potential sources of tension, as well as dispersed wisdom and useful ideas 
that can be leveraged in practice. Understanding how change is perceived by different actors enables management to take appropriate actions that ensure successful change. A top-down approach to implementing innovations and changes in safety-critical megaprojects may not always produce controlled outcomes because of the equivocality that fragmented sensemaking processes create. Managers should therefore pay close attention to planning and preparing for change, including early engagement with stakeholders at different organizational levels.

Here, the new method was introduced for better management of the licensing process and to ensure that safety-related design documentation complied with regulatory requirements. However, the interviewees' stories suggest that adoption of the new method also had significant implications for overall project implementation in terms of gradual changes in work practices and relationships between actors, as well as improved work coordination and a better understanding of the competences and capabilities required for project success. These implications need to be recognized and managed in order to capture potential benefits while mitigating negative impacts on safety. Implementation of a new method can be understood as a boundary object that offers project actors a shared space and vocabulary that facilitates collaboration and a common understanding of what is expected.

As these findings indicate, the sensemaking process in large and complex project networks is often fragmented, and managers need to be aware of the scale and implications of perceived ambiguity, which may affect relationships and communication by generating multiple interpretations in a fastpaced project context.

\section{Limitations and further research}

The single case study approach has some limitations in terms of generalizability. Nevertheless, it elicits new perspectives and knowledge in relation to sensemaking processes and their influence on innovation adoption in a nuclear project. In corporating the views of other network actors, such as the regulator and suppliers, would undoubtedly provide a richer and more holistic picture, serving as a platform for further research exploring differences in sensemaking across different actors. Beyond the individual narratives assembled here, further research could usefully explore collective sensemaking processes within the project network. Future research could also build on the present study by exploring sensemaking processes in multiple nuclear project contexts, adopting a contingency approach to take account of potential cultural and organizational differences.

More generally, there is scope to explore how the distinctive characteristics of the nuclear industry impact sensemaking processes. As these stories and narratives exhibited some degree of overlap, future research should analyze the interconnections between stories in greater depth, as well as addressing their temporal embeddedness and ordering in the context of innovation adoption. Finally, as the innovation described here also involved change management, it would be useful to establish more robust links between the literatures on project change management and uncertainty management.

\section{References}

Ahola, T., Ruuska, I., Artto, K. and Kujala, J. (2014), "What is project governance and what are its origins?" International Journal of Project Management, Vol. 32 No. 8, pp. 1321-1332. 
Alderman, N., Ivory, C., McLoughlin, I. and Vaughan, R. (2005), "Sense-making as a process within complex service-led projects", International Journal of Project Management, Vol. 23 No. 5, pp. 380 385 .

Alexander, C. (1964), Notes on the Synthesis of Form. Harvard University Press, Cambridge, MA.

Artto, K., Ahola, T. and Vartiainen, V. (2016), "From the front end of projects to the back end of operations: Managing projects for value creation throughout the system lifecycle", International Journal of Project Management, Vol. 34 No. 2, pp. 258-270.

Artto K. and Kujala J. (2008), "Project business as a research field", International Journal of Managing Projects in Business, Vol. 1 No. 4, pp. 469-497.

Berger, P.L. and Luckmann, T. (1967), The Social Construction of Reality: A Treatise in the Sociology of Knowledge, Penguin, London.

Brady, T. and Davies, A. (2004), "Building solution capabilities: From exploratory to exploitative learning", Organization Studies, Vol. 25 No. 9, pp. 1601-1621.

Brady, T., Davies, A., Gann, D. and Rush, H. (2007), "Learning to manage mega projects: The case of BAA and Heathrow Terminal 5", Project Perspectives Vol. XXIX, pp. 32-39.

Brookes, N.J. and Locatelli, G. (2015), "Power plants as megaprojects: Using empirics to shape policy, planning, and construction management", Utilities Policy, Vol. 36, pp. 57-66.

Brown, A. D., Stacey, P., and Nandhakumar, J. (2008). Making sense of sensemaking narratives. Human Relations, 61(8), 1035-1062.

Choi, T.Y., Dooley, K.J.and Rungtusanatham, M. (2001), "Supply networks and complex adaptive systems: Control versus emergence", Journal of Operations Management, Vol. 19 No. 3, pp. 351-366.

Christianson, M.K., Farkas, M.T., Sutcliffe, K.M. and Weick, K.E. (2009), "Learning through rare events: Significant interruptions at the Baltimore and Ohio Railroad Museum", Organization Science, Vol. 20 No. 5, pp. 846-860.

Cleland, D.I. and King, W.R. (1968), Systems Analysis and Project Management, McGraw-Hill, New York, NY.

Crossan, M.M.and Apaydin, M. (2010), "A multi-dimensional framework of organizational innovation: A systematic review of the literature”, Journal of Management Studies, Vol. 47 No. 6, pp. 1154-1191.

Daft, R.L. and Weick, K.E. (1984), "Toward a model of organizations as interpretation systems", Academy of Management Review, Vol. 9, pp. 284-295.

Davies, A. (2004), "Moving base into high-value integrated solutions:A value stream approach", Industrial and Corporate Change, Vol. 13 No. 5, pp. 727-756.

Davies, A., MacAulay, S., DeBarro, T. and Thurston, M. (2014), "Making innovation happen in a megaproject: London's crossrail suburban railway system", Project Management Journal, Vol. 45 No. 6, pp. $25-37$.

DeBarro, T., MacAulay, S., Davies, A., Pelton, J., Wolstenholme, W. and Gann, D.M. (2015), "From mantra to method: Lessons from managing innovation at Crossrail", New Civil Engineer, Vol. 168 No. 4, pp. 18. 
DeFillippi, R. and Sydow, J. (2016), "Project networks: Governance choices and paradoxical tensions", Project Management Journal, Vol. 47 No. 5, pp. 1-12.

Dhanaraj, C. and Parkhe, A. (2006), "Orchestrating innovation networks", Academy of Management Review, Vol. 31 No. 3, pp. 659-669.

Dodgson, M., Gann, D., MacAulay, S. and Davies, A. (2015), "Innovation strategy in new transportation systems: The case of Crossrail", Transportation Research Part A: Policy and Practice, Vol. 77, pp. 261-275.

Dutton, J.E. and Dukerich, J.M. (1991), "Keeping an eye on the mirror: Image and identity in organizational adaptation", Academy of Management Journal, Vol. 34, pp. 517-554.

Dyer, R. (2016), "Cultural sense-making integration into risk mitigation strategies towards megaproject success", International Journal of Project Management (in press, corrected proof).

Fellows, R. and Liu, A. (2016), "Sensemaking in the cross-cultural contexts of projects", International Journal of Project Management, Vol. 34 No. 2, pp. 246-257.

Floricel, S. and Miller, R. (2001), "Strategizing for anticipated risks and turbulence in large-scale engineering projects", International Journal of Project Management, Vol. 19, pp. 445-455.

Flyvbjerg, B., Bruzelius, N. and Rothengatter, W. (2003), Megaprojects and Risk: An Anatomy of Ambition, Cambridge University Press, Cambridge.

Gil, N. and Tether, B. (2011), "Project risk management and design flexibility: Analysing a case and conditions of complementarity", Research Policy, Vol. 40 No. 3, pp. 415-428.

Gioia, D.A. and Thomas, J.B. (1996), "Institutional identity, image, and issue interpretation: Sensemaking during strategic change in academia", Administrative Science Quarterly, Vol. 41 No. 3, pp. 370-403.

Hayes, J. and Maslen, S. (2015) "Knowing stories that matter: learning for effective safety decision-making", Journal of Risk Research,Vol.18 No. 6, pp. 714-726

Henneberg, S. C., Naudé, P.and Mouzas, S. (2010), "Sense-making and management in business networksSome observations, considerations, and a research agenda", Industrial Marketing Management, Vol. 39 No. 3, pp. 355-360.

Hinterhuber, A. (2002), "Value chain orchestration in action and the case of the global agrochemical industry", Long Range Planning, Vol. 35 No. 6, pp. 615-635.

Hollnagel, E. (2014), Safety-I and Safety-II: The Past and Future of Safety Management, Ashgate.

Invernizzi, D.C., Locatelli, G. and Brookes N.J. (2016), "Managing social challenges in the nuclear decommissioning industry: A responsible approach towards better performance", International Journal of Project Management (in press).

Jarillo, J.C. (1988), “On strategic networks”, Strategic Management Journal, Vol. 9 No. 1, pp. 31-41.

Järvensivu, T. and Möller, K. (2009), "Metatheory of network management: A contingency perspective", Industrial Marketing Management, Vol. 38 No. 6, pp. 654-661.

Jones, C., Hesterly, W.S. and Borgatti, S.P. (1997), “A general theory of network governance: Exchange conditions and social mechanisms", Academy of Management Review, Vol. 22 No. 4, pp. 911-945. 
Kujala J., Aaltonen K., Gotcheva N. and Pekuri A. (2016), "Key dimensions of project network governance and implications for safety in nuclear industry projects", paper presented at EURAM 2016 annual conference, 1-4 June 2016, Paris.

Levitt, B. and March, J.G. (1995), "Chester I. Barnard and the Intelligence of Learning”, in Williamson, O.E. (Ed.), Organization Theory: From Chester Barnard to the Present and Beyond, Oxford University Press, New York, pp. 11-37.

Lundrigan, C., Gil, N. and Puranam, P. (2014), "The (under)performance of mega-projects: A metaorganizational perspective", working paper, University of Manchester, December.

March, J.G. and Sutton, R.I. (1997), "Organizational performance as a dependent variable”, Organization Science, Vol. 8, pp. 698-706.

Matinheikki J., Artto K., Peltokorpi A. and Rajala R. (2016), "Managing inter-organizational networks for value creation in the front-end of projects", International Journal of Project Management, Vol. 34 No. 7, pp. 1226-1241.

Maclean, M., Harvey, C. and Chia, R. (2012). "Sensemaking, storytelling and the legitimization of elite business careers". Human Relations, Vol. 65 No. 1, pp. 17-40.

Meyer J.W.and Rowan B. (1977), "Institutionalized organizations: Formal structure as myth and ceremony", American Journal of Sociology, Vol. 83 No. 2, pp. 340-363.

Miller, R. and Lessard, D. (2008), "Evolving strategy: Risk management and the shaping of mega-projects", in Priemus, H., Flyvbjerg, B. and van Wee, B. (Eds.), Decision-Making on Mega-Projects: Cost-Benefit Analysis, Planning, and Innovation, Edward Elgar, Cheltenham, UK.

Miller, R. and Lessard, D. (2001a), The Strategic Management of Large Engineering Projects: Shaping Risks, Institutions and Governance, MIT Press, Cambridge, MA.

Morris, P.W.G. (1983), "Managing project interfaces—Key points for project success", in Cleland, D.I. and King, W.R. (Eds.), Project Management Handbook, Van Nostrand, New York, pp. 16-55.

Morris, P.W.G. (2013), Reconstructing Project Management, John Wiley and Sons, Chichester, UK.

Morris, P.W.G. and Hough, G.H. (1987), The Anatomy of Major Projects-A Study of the Reality Of Project Management, John Wiley and Sons, Chichester, UK.

Möller, K. and Rajala, A. (2007), "Rise of strategic nets—new modes of value creation", Industrial Marketing Management, Vol. 36 No. 7, pp. 895-908.

Möller, K., Rajala, A. and Svahn, S. (2005), "Strategic business nets-their type and management”, Journal of Business Research, Vol. 58 No. 9, pp. 1274-1284.

Müller-Seitz, G. (2012), "Leadership in interorganizational networks: A literature review and suggestions for future research", International Journal of Management Reviews, Vol. 14 No. 4, pp. 428-443.

Nightingale, P. and Brady, T. (2011), "Projects, paradigms and predictability", in Cattani, G., Ferriani, S., Frederiksen, L. and Täube, F. (Eds.), Project-Based Organizing and Strategic Management, Emerald, Bingley, UK, pp. 83-112.

Olson, M. (1965), The Logic of Collective Action, Harvard University Press, Cambridge, MA. 
Orr, R.J. and Scott, W.R. (2008), "Institutional exceptions on global projects: A process model”, Journal of International Business Studies, Vol. 39, pp. 562-588.

Ostrom, E. (1990), Governing the Commons: The Evolution of Institutions for Collective Action, Cambridge University Press, Cambridge, UK.

Papadimitriou, K.and Pellegrin, C. (2007), "Dynamics of a project through Intermediary Objects of Design (IODs): A sensemaking perspective", International Journal of Project Management, Vol. 25 No. 5, pp. 437-445.

Parolini, C. (1999), The Value Net: A Tool for Competitive Strategy, Wiley, Chichester, UK.

Pinto, J.K. and Rouhiainen, P. (2001), Building Customer-Based Project Organizations, John Wiley and Sons, New York, NY.

Pollack, J., Costello, K. and Sankaran. S. (2013), “Applying Actor-Network Theory as a sensemaking framework for complex organizational change programs", International Journal of Project Management, Vol. 31 No. 8, pp. 1118-1128.

Provan, K.G. and Kenis, P. (2008), "Modes of network governance: Structure, management, and effectiveness", Journal of Public Administration Research and Theory, Vol. 18 No. 2, pp. 229-252.

Raab, J. and Kenis, P. (2009), "Heading toward a society of networks: Empirical developments and theoretical challenges", Journal of Management Inquiry, Vol. 18 No. 3, pp. 198-210.

Reiman, T., Pietikäinen, E. and Oedewald, P. (2010), "Multilayered approach to patient safety culture", Quality and Safety in Health Care, Vol. 19, pp. 1-5.

Reiman, T. and Rollenhagen, C. (2011), "Human and organizational biases affecting the management of safety", Reliability Engineering and System Safety, Vol. 96, pp. 1263-1274.

Reiman, T. and Rollenhagen, C. (2014), "Does the concept of safety culture help or hinder systems thinking in safety?" Accident Analysis and Prevention, Vol. 68, pp. 5-15.

Reiman, T., Pietikäinen, E., Oedewald, P. and Gotcheva, N. (2012), "System modeling with the DISC framework: Evidence from safety-critical domains", Work, Vol. 41, pp. 3018-3025.

Rerup, C. and Feldman, M.S. (2011), "Routines as a source of change in organizational schemata: The role of trial-and-error learning”, Academy of Management Journal, Vol. 54 No. 3, pp. 577-610.

Ruuska, I., Ahola, T., Artto, K., Locatelli, G. and Mancini, M. (2011), “A new governance approach for multi-firm projects: Lessons from Olkiluoto 3 and Flamanville 3 nuclear power plant projects", International Journal of Project Management, Vol. 29 No. 6, pp. 647-660.

Saunders, F.C. and Townsend, E.A. (2018), "Delivering new nuclear projects: A megaprojects perspective", International Journal of Managing Projects in Business, https:// doi.org/10.1108/IJMPB-03-2018-0039.

Sayles, L.R. and Chandler, M.K. (1971), Managing Large Systems: Organizations for the Future, Harper and Row, New York, NY.

Schein, E. (1992), Organizational Culture and Leadership (2nd ed.), Jossey Bass, San Francisco, CA.

Scott, W.R., Levitt, R.E. and Orr, R.J. (2011), Global Projects: Institutional and Political Challenges, Cambridge University Press, New York, NY. 
Sergeeva, N. (2014). "Understanding of labelling and sustaining of innovation in construction: A sensemaking perspective”. Engineering Journal Organization Journal, Vol. 4 No. 1, pp. 31-43.

Shenhar, A.J., Dvir, D., Levy, O. and Maltz, A. (2001), "Project success-a multidimensional, strategic concept", Long Range Planning, Vol. 34 No. 6, pp. 699-725.

Simon, H. (1962), "The architecture of complexity", Proceedings of the American Philosophical Society, Vol. 106 No. 6, pp. 467-482.

Simon, H.A. (1969), The Sciences of the Artificial, MIT Press, Cambridge, MA.

Thiry, M. (2001), "Sensemaking in value management practice", International Journal of Project Management, Vol. 19 No. 2, pp. 71-77.

Tukiainen, S., Aaltonen, K. and Murtonen, M. (2010), "Coping withh an unexpected event: Project managers' contrasting sensemaking in a stakeholder conflict in China”, International Journal of Managing Projects in Business, Vol. 3 No. 3, pp. 526-543.

Turkulainen, V., Ruuska, I., Brady, T. and Artto, K. (2015), "Managing project-to-project and project-toorganization interfaces in programs: Organizational integration in a global operations expansion program", International Journal of Project Management, Vol. 33, pp. 816-827.

Turner, J.R. (2014), The Handbook of Project-Based Management: Leading Strategic Change in Organizations (4th ed.), McGraw-Hill Education, New York, NY.

Van de Ven, A., Polley, D., Garud, R. and Venkataraman, S. (2008), The Innovation Journey, Oxford University Press, New York, NY.

Von Bertalanffy, L. (1950), "The theory of open systems in physics and biology", Science, NS 111/2872, pp. 23-29.

Vaara, E. (2002), "On the discursive construction of success/failure in narratives of post- merger integration", Organization Studies, Vol. 23, pp. 211-248.

Vaara, E. (2003), "Post-acquisition integration as sensemaking: Glimpses of ambiguity, confusion, hypocrisy, and politicization", Journal of Management Studies, Vol. 40, pp. 859-894.

Vaara, E., Sonenshein, S., Boje, D. (2017), "Narratives as sources of stability and change in organizations: Approaches and directions for future research", Academy of Management Annals, Vol. 10 No 1, pp. 495-560.

Weick, K.E. (1995), Sensemaking in Organizations, Sage Publications, Thousand Oaks, CA.

Weick, K.E. (1999), "Sensemaking as an organizational dimension of global change", in Cooperrider, D.L. and Dutton, J.E. (Eds.), Organizational Dimensions of Global Change, Sage Publications, Thousand Oaks, CA, pp. 39-56.

Weick, K.E., Sutcliffe, K.M. and Obstfeld, D. (2005), “Organizing and the process of sensemaking”, Organization Science, Vol. 16, pp. 409-421.

Zidane, Y.J.-T., Johansen, A. and Ekambaram, A. (2013), "Megaprojects - challenges and lessons learned", Procedia-Social and Behavioral Sciences, Vol. 74, pp. 349-357. 
Table 1: Summary of the empirical findings

\begin{tabular}{|c|c|c|c|c|}
\hline 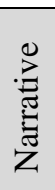 & $\begin{array}{l}\text { Rationale for adopting the } \\
\text { innovation }\end{array}$ & $\begin{array}{l}\text { Key actors (subjects) and } \\
\text { potential objects of the } \\
\text { innovation }\end{array}$ & $\begin{array}{l}\text { Key events } \\
\text { related to } \\
\text { adoption of the } \\
\text { innovation }\end{array}$ & $\begin{array}{l}\text { Interpreted consequences } \\
\text { and potential challenges of } \\
\text { innovation adoption }\end{array}$ \\
\hline 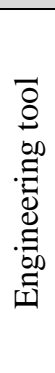 & $\begin{array}{l}\text { Need for a technical tool to } \\
\text { elaborate and manage } \\
\text { numerous strict and } \\
\text { complex requirements by } \\
\text { providing structure, } \\
\text { transparence and } \\
\text { traceability }\end{array}$ & $\begin{array}{l}\text { Owner's project } \\
\text { management and tool } \\
\text { developer company }\end{array}$ & $\begin{array}{l}\text { Training by tool } \\
\text { developer } \\
\text { company }\end{array}$ & $\begin{array}{l}\text { The tool helps to coordinate } \\
\text { the work, makes review and } \\
\text { approval processes more } \\
\text { efficient, proves the } \\
\text { correctness of the design and } \\
\text { improves safety and } \\
\text { understanding of regulatory } \\
\text { requirements }\end{array}$ \\
\hline 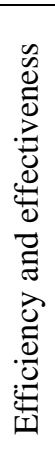 & $\begin{array}{l}\text { Need to focus on technical } \\
\text { benefits of adopting the } \\
\text { tool (e.g., improved } \\
\text { efficiency, coordination, } \\
\text { quality and safety) }\end{array}$ & $\begin{array}{l}\text { All project actors involved } \\
\text { in the design and approval } \\
\text { processes }\end{array}$ & $\begin{array}{l}\text { Meetings and } \\
\text { workshops; } \\
\text { document review } \\
\text { process }\end{array}$ & $\begin{array}{l}\text { Perceived short-term } \\
\text { drawbacks (e.g., additional } \\
\text { work) and long-term } \\
\text { benefits (e.g., resource } \\
\text { savings, predictability, long- } \\
\text { term success) }\end{array}$ \\
\hline 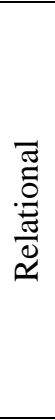 & $\begin{array}{l}\text { Need to facilitate } \\
\text { relationship building in the } \\
\text { project network-tool is } \\
\text { seen as a catalyst for } \\
\text { relational interaction }\end{array}$ & $\begin{array}{l}\text { Key network of project } \\
\text { actors and their relationships }\end{array}$ & $\begin{array}{l}\text { Training, } \\
\text { meetings and } \\
\text { workshops for } \\
\text { building } \\
\text { relationships and } \\
\text { trust and } \\
\text { facilitating } \\
\text { learning among } \\
\text { project actors }\end{array}$ & $\begin{array}{l}\text { Establishment of joint } \\
\text { language (structured } \\
\text { terminology), improved } \\
\text { information sharing, } \\
\text { communication and trust } \\
\text { development; building } \\
\text { shared and collective } \\
\text { understanding beyond the } \\
\text { design process }\end{array}$ \\
\hline 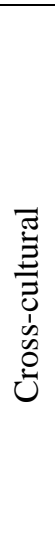 & $\begin{array}{l}\text { Need to bridge the cultural } \\
\text { distance between different } \\
\text { nationalities involved in } \\
\text { the project } \\
\text { Need for localized } \\
\text { knowledge of licensing } \\
\text { requirements and ways of } \\
\text { operating }\end{array}$ & $\begin{array}{l}\text { Objects of change are the } \\
\text { network's international } \\
\text { actors } \\
\text { Active agency enacted by } \\
\text { project owner and regulatory } \\
\text { body }\end{array}$ & $\begin{array}{l}\text { Meetings and } \\
\text { workshops; } \\
\text { document review } \\
\text { process }\end{array}$ & $\begin{array}{l}\text { Tool creates a shared } \\
\text { technical space in which } \\
\text { other cross-cultural issues } \\
\text { can also be discussed. } \\
\text { Tool helps to standardize } \\
\text { and harmonize } \\
\text { communication. } \\
\text { Different nationalities } \\
\text { equated with different ways } \\
\text { of thinking about design; } \\
\text { tool helps to build collective } \\
\text { capabilities }\end{array}$ \\
\hline
\end{tabular}




\begin{tabular}{|c|c|c|c|c|}
\hline $\begin{array}{c}\overline{0} \\
\stackrel{\Xi}{0} \\
\dot{0}\end{array}$ & $\begin{array}{l}\text { Need to reduce uncertainty } \\
\text { and enable stronger control } \\
\text { of the design process }\end{array}$ & $\begin{array}{l}\text { The key objects of change } \\
\text { are the contractors } \\
\text { responsible for design; } \\
\text { project owner's operational } \\
\text { management is seen as the } \\
\text { subject }\end{array}$ & Meetings, training & $\begin{array}{l}\text { Better control of the } \\
\text { schedule } \\
\text { Confidence in monitoring of } \\
\text { the project network } \\
\text { Improved capability to } \\
\text { detect early indicators of } \\
\text { schedule delays or } \\
\text { coordination issues }\end{array}$ \\
\hline$\underset{\stackrel{\Xi}{0}}{\stackrel{0}{I}}$ & $\begin{array}{l}\text { Need for project "savior" } \\
\text { New and proven approach } \\
\text { for design and licensing } \\
\text { process needed because } \\
\text { supplier's traditional } \\
\text { practices were not } \\
\text { successful in this context }\end{array}$ & $\begin{array}{l}\text { Supplier and major actors in } \\
\text { the supply chain as the } \\
\text { object of change }\end{array}$ & $\begin{array}{l}\text { Meetings and } \\
\text { workshops; } \\
\text { document review } \\
\text { process }\end{array}$ & $\begin{array}{l}\text { Implementing the tool brings } \\
\text { hope for the future } \\
\text { Main implication of change } \\
\text { is the shared perception that } \\
\text { the project is on the right } \\
\text { track }\end{array}$ \\
\hline 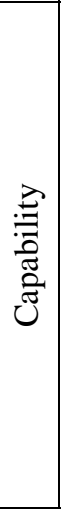 & $\begin{array}{l}\text { Need to create } \\
\text { organizational and project } \\
\text { network-level capabilities } \\
\text { to manage complex design } \\
\text { process } \\
\text { Need to make tacit } \\
\text { knowledge explicit and } \\
\text { retain it in the organization } \\
\text { and the project network }\end{array}$ & $\begin{array}{l}\text { The object of change is the } \\
\text { project network (mainly the } \\
\text { supplier) } \\
\text { The subject of change is the } \\
\text { regulator and the power } \\
\text { company that developed the } \\
\text { tool }\end{array}$ & $\begin{array}{l}\text { Training, use of } \\
\text { databases and } \\
\text { standardized } \\
\text { document } \\
\text { structures to } \\
\text { manage } \\
\text { requirements } \\
\text { Involving the tool } \\
\text { developer } \\
\text { company as a } \\
\text { consultant }\end{array}$ & $\begin{array}{l}\text { Tool is seen as a novel } \\
\text { competence and capability } \\
\text { developer that requires high } \\
\text { level skills and big picture } \\
\text { thinking } \\
\text { Tool encourages new } \\
\text { learning practices in the } \\
\text { project network } \\
\text { Tool minimizes risks related } \\
\text { to person-centric knowledge }\end{array}$ \\
\hline 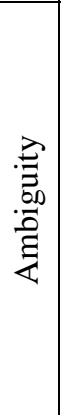 & $\begin{array}{l}\text { Need to adapt to a tool that } \\
\text { is perceived as complex, } \\
\text { heavy and difficult to learn }\end{array}$ & $\begin{array}{l}\text { The objects of change are } \\
\text { the owner organization and } \\
\text { the supplier's side }\end{array}$ & $\begin{array}{l}\text { Project meetings } \\
\text { with key suppliers } \\
\text { to justify use of } \\
\text { the tool }\end{array}$ & $\begin{array}{l}\text { Implementation of the tool } \\
\text { triggered a complex change } \\
\text { process in the project } \\
\text { network that raised anxiety, } \\
\text { different opinions and } \\
\text { tensions } \\
\text { Uncertainty: first time the } \\
\text { tool has been used with this } \\
\text { new scope }\end{array}$ \\
\hline 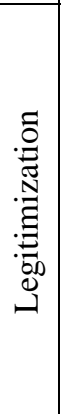 & $\begin{array}{l}\text { Need to create } \\
\text { documentation that meet } \\
\text { the local nuclear safety } \\
\text { regulatory requirements, as } \\
\text { well as other requirements } \\
\text { (contract, international } \\
\text { standards) }\end{array}$ & $\begin{array}{l}\text { Key actors are the regulator } \\
\text { and the tool developer } \\
\text { company and the key } \\
\text { companies from the } \\
\text { supplier's side }\end{array}$ & $\begin{array}{l}\text { Meetings and } \\
\text { documents review } \\
\text { process to verify } \\
\text { that plant design } \\
\text { meets regulatory } \\
\text { requirements for } \\
\text { safety and other } \\
\text { requirements (e.g. } \\
\text { quality) }\end{array}$ & $\begin{array}{l}\text { Tool requires additional } \\
\text { documentation to be created } \\
\text { Questions about extent of } \\
\text { technical and organizational } \\
\text { benefits this documentation } \\
\text { provides by improving co- } \\
\text { ordination between project } \\
\text { actors }\end{array}$ \\
\hline
\end{tabular}

